\title{
Neuropsychologic Deficits in Schizophrenia Relation to Social Function and Effect of Antipsychotic Drug Treatment
}

\author{
Herbert Y. Meltzer, M.D., Paul A. Thompson, Ph.D., Myung A. Lee, M.D., \\ and Rakesh Ranjan, M.D.
}

Cognitive impairment is present in the majority of schizophrenic patients, even at the onset of psychosis. It is a relatively stable characteristic in most patients, usually with little progression over the course of illness, but sometimes progresses to severe dementia. The results of studies of the effects of typical neuroleptic drugs on cognitive functioning in schizophrenia are conflicting. Clozapine, which has superior antipsychotic effects compared to typical neuroleptic drugs, has been reported to improve executive function, verbal fluency, attention, and recall memory in two of three studies. Cognitive measures predict work function and overall outcome on clozapine as assessed by the Global Assessment Scale and Qualityof-Life Scale in neuroleptic - resistant schizophrenia. Improvement in cognitive function by clozapine may be a major reason for expanding its currently limited utilization. [Neuropsychopharmacology 14:27S-33S, 1996]
KEY WORDS: Schizophrenia; Cognitive function; Neuroleptic; Quality of life

Cognitive impairment in patients with schizophrenia appears to be diffuse and extensive (Braff et al. 1991). Although attentional deficits have been considered to be the primary cognitive deficit in schizophrenia by some (Seidman 1983; Neuchterlein and Dawson 1984; Oltmanns 1978), there is evidence that even after correction for problems in attention, there are persistent deficits in executive function, learning and memory, verbal intelligence, and language function skills (Kenny and Meltzer

From the Laboratory of Biological Psychiatry, Department of Psychiatry, Case Western Reserve University School of Medicine, Cleveland, Ohio.

Dr. Myung A. Lee is currently at the Department of Psychiatry, State University of New York, 462 Grider Street, Buffalo, NY 14215. Address correspondence to: Herbert Y. Meltzer, M.D., Douglas D. Bond Professor of Psychiatry, Department of Psychiatry, University Hospitals of Cleveland, 11100 Euclid Avenue, Cleveland, $\mathrm{OH}$ 441065000 .

This article was presented at the integrated symposium "A New Understanding: Neurological Basis and Long-Term Outcome of Schizophrenia" chaired by Herbert Y. Meltzer and Leif H. Lindström at the CINP Congress, June 28, 1994, in Washington, D.C.
1991). Neuropsychologic tests, which have been validated in patients with a variety of known brain lesions, are the best means of assessing cognitive dysfunction in schizophrenia. Such tests enable some degree of localization of dysfunction to specific brain areas, but multiple brain areas are often involved in generating correct responses. With selected groups of these tests, evidence of diffuse dysfunction, including the frontal lobes, the temporal lobe, and hippocampus, has been reported in patients with schizophrenia by a number of investigators (Bilder et al. 1985; Braff et al. 1991; Goldberg et al. 1993b; Kenny and Meltzer 1991; Hagger et al. 1993; Saykin et al. 1991; Heaton et al. 1994). Depending on the tests used, cut-off scores for normal performance, and the comparison group, $40 \%$ to $90 \%$ of schizophrenic patients may be impaired cognitively (Saykin et al. 1991; Heaton et al. 1994; Meltzer et al. unpublished observations). Studies of first-episode schizophrenic patients suggest that cognitive dysfunction is present at the onset of psychosis (Hoff et al. 1991, 1992a,b; Sweeney at al. 1991, 1992; Bilder et al. 1991, 1992; Saykin et al. 1994). Follow-up studies suggest that the deficit in neuropsychologic function is not particularly progressive in the 
large majority of patients (Heaton et al. 1994; Goldberg et al. 1988). However, we will present some evidence to the contrary.

We have examined cognitive impairment in 64 chronic treatment-resistant schizophrenic patients (age: $36.2 \pm$ 9.7 years, duration of illness: $15.7 \pm 7.7$ years) and in 35 recent onset treatment-responsive schizophrenic patients (age: $25.6 \pm 5.7$ years, duration of illness: $2.0 \pm 2.3$ years). The Digit Symbol Substitution test (a test of attention) and the Wechsler Intelligence Scale for ChildrenRevised (WISC-R) Maze (a test of executive function) were significantly more impaired in treatment-responsive schizophrenia. However, no differences were found in six other cognitive tests: the Consonant Trigram (a test of primary memory) and Controlled Word Association tests (tests of verbal fluency), Verbal List Learning (VLL)-Immediate and Delayed Recall (tests of recall memory), and Wisconsin Card Sorting test (WCST), another test of executive function. Thus, there is some evidence from these data for a relationship between poor performance on selected cognitive tests, age, duration of illness, and neuroleptic-response, but, because of intercorrelations, it is not clear which of these factors is primary. In a subsequent analysis in which cognitive test scores were adjusted for age and IQ, there were no significant differences between neuroleptic-resistant and -responsive schizophrenic patients (Meltzer et al. unpublished data). These studies were obtained at the time of initial evaluation, mainly in antipsychotic drugfree patients. In addition, in treatment-resistant schizophrenia, we found significant negative correlations between duration of illness and performance on the following tests: WCST-Category and the WISC-R Maze and Consonant Trigram test. A positive correlation was found with SCST Percent Perseveration and duration of illness indicative of worse performance as the illness progresses. These results suggest there may be progressive deterioration in some cognitive areas during the course of the illness.

\section{EFFECT OF TYPICAL NEUROLEPTICS}

The effects of neuroleptic drugs on cognitive performance have been reviewed (Cassens et al. 1990; King 1990; Bilder et al. 1992). As summarized by King (1990), sedative phenothiazines may depress psychomotor function and sustained attention. Performance on selected memory tests as well as a maze test, which is believed to provide a measure of frontal lobe function, have been reported to be impaired by neuroleptic treatment (Medalia et al. 1988; Porteus 1957; Porteus and Barclay 1957; Judson and McCasland 1960; Spohn and Strauss 1989; Cassens et al. 1990). Other studies of schizophrenic patients also report no improvement (Berman et al. 1986) or worsening of cognitive function with neuroleptic treatment (Erickson 1984; Cleghorn 1990). As will be discussed later, we have found only a modest effect of typical neuroleptic drugs on cognitive function at a 12-month follow-up. However, King (1990) concluded that cognitive function and attention may improve with neuroleptic treatment if there is remission of psychotic symptoms. In addition, Nestor et al. (1991) reported that neuroleptic withdrawal may impair attentional processes. At 12-month follow-up, typical neuroleptic drugs have been reported to improve attention, verbal memory, executive function, and motor performance in 39 schizophrenic patients (Sweeney et al. 1991). Bilder et al. (1991) also found overall improvement in most neuropsychologic functions during a 1-year period in 28 first-episode schizophrenic patients; relatively consistent and significant improvement was found on tests of motor function, learning, and memory, but not attention. Thus, some studies report worsening, improvement, or no change in cognitive function in schizophrenia with typical neuroleptic treatment. These discrepancies may be due, in part, to differences in patient populations, specific tests used, and response of psychopathology to neuroleptic drugs.

\section{EFFECT OF CLOZAPINE}

Clozapine ${ }^{1}$ is the most effective treatment for psychopathology in neuroleptic-resistant schizophrenia (Kane et al. 1988; Meltzer et al. 1992a) and may also be more effective in this regard in neuroleptic-responsive schizophrenic patients (Meltzer 1992b). Clozapine also has a variety of differences in mechanism of action compared to typical neuroleptics (Meltzer 1991; Meltzer et al. in press). It is, therefore, possible that its effects on cognitive function might differ from typical neuroleptic drugs. However, Goldberg et al. (1993a) reported no beneficial effect of clozapine on cognitive function in 15 neuroleptic-resistant, mainly schizophrenic patients. Baseline assessments were obtained while patients were receiving neuroleptic-treatment. After a follow-up of 3 to 24 months (mean $=15$ months), no change in any of the tests (e.g., WCST, Digit Symbol, Wechsler Memory Scale, and Trials B) was found, despite considerably clinical improvement. These results are in contrast with those of our group (Hagger et al. 1993). In a study of 36 neuroleptic-resistant schizophrenic $(N=32)$ and schizoaffective $(N=4)$ patients, we found significant improvement in the Controlled Word Association Test, Category Instance Generation, the Digit Symbol Substitution, VLL-Immediate Recall and WISC-R Maze at 6 weeks, 6 months, or both. Improvement was most marked in neuroleptic responders. Scores on the WISC-R Maze and Controlled Word Association tests were within the

\footnotetext{
${ }^{1}$ Clozapine is available under the trade names Clozaril and Leponex.
} 
normal range after 6 months. Similar results were found after 12 months of treatment (Meltzer et al. unpublished).

We have reported preliminary results of a study of the effect of clozapine versus typical neuroleptic drugs in recent-onset neuroleptic-responsive patients (Lee et al. 1994). In this study, 47 patients who were randomly assigned to typical neuroleptic drugs or clozapine were examined. In the clozapine-treated group $(N=24)$, significant improvement was found in the Digit Symbol, the Category Instance Generation, Controlled Word Association, and the WCST Percent Perseveration after 6 weeks, 6 months, or 12 months of treatment. Improvement in the WCST Card Sorting Category and Delayed Recall tests was observed at 12 months in the neuroleptic-treated patients $(N=23)$. In addition, the clozapine-treated group was significantly more improved compared to the typical neuroleptic-treated groups in the Digit Symbol and Controlled Word Association tests at 6 weeks, 6 months, and 12 months. This is an ongoing study that will be reported in full subsequently.

Recently, Buchanan et al. (1994) reported the results of a study comparing clozapine or haloperidol plus benztropine in a 10-week parallel groups double-blind comparison in 19 neuroleptic-resistant patients. A comprehensive assessment of Executive/Attention, Visuospatial Function and Memory was obtained at baseline, while the patients were on fluphenazine, at the end of 10 weeks of the double-blind study, and at the end of 1 year of open clozapine treatment $(N=33)$. At the end of 10 weeks, performance on the Category Fluency and WAIS-R Block Design was significantly better in the clozapine-treated patients. This was due, in part, to a worsening of performance of the haloperidol-treated group on these two measures. After 1 year of clozapine treatment, significant improvement was found in Verbal Fluency, Mooney Faces Closure, and WAIS-R Block design. There were trends for improvement in Stroop Color Word Interference Test, Category Fluency, and Logical Memory of the Wechsler Memory Scale. The Trials B score was worse. There was evidence for greater improvement in four of the six neuropsychologic measures that exhibited improvement at 1 year between that time and the 10-week assessment. The authors concluded that their results for verbal and category fluency were consistent with the data of Hagger et al. (1993).

H. S. Lee (personal communication, 7/94) also found that at the end of 12 weeks of treatment with clozapine, significant improvement was observed in a test of attention (Digit Span) and visual perception (Judgement of Line Orientation) in 21 chronic schizophrenic patients. Further study of the effect of clozapine on cognition is needed to resolve the discrepancies between the two positive studies and the negative study of Goldberg et al. (1993).

\section{NEUROPSYCHOLOGIC IMPAIRMENT, SOCIAL FUNCTION, AND OVERALL OUTCOME}

It is well known that the outcome of schizophrenia in terms of quality of life, work function, and social function is usually poor. The extent to which this is due to cognitive impairment rather than psychopathology has been little studied.

Several studies have indicated a relationship between cognitive impairment and outcome, as measured globally, or work function in schizophrenia. Breier et al (1991) conducted a follow-up study (range 2 to 12 years, mean $6 \pm 3$ years) of 58 chronic schizophrenic patients. Only $20 \%$ of the patients had a good outcome. The WCST-Percent Perseveration measure at follow-up (available in 32 patients) was significantly negatively correlated with social function as measured by the Level of Functioning scale (Hawk et al. 1975) and global outcome as measured by the Global Assessment Scale (GAS; Spitzer et al. 1979). It was also inversely correlated with negative symptoms but not positive symptoms. Similar results were obtained with the Trials A, Trials B, and Controlled Word Association tests, which the authors considered measures of frontal lobe functioning. Meuser et al. (1991) have suggested that memory function was directly related to the ability to acquire social skills in a group of schizophrenic patients.

Bellack (1992) has discussed the role of cognitive impairment in social disability, suggesting that social function requires such cognitive skills as face and affect recognition, recall of past interactions, executive functions, and language skills. Bellack et al. (1990) hypothesized that social problem solving requires higher level reasoning, episodic and semantic memory, sustained attention, and high processing capacity and has proposed that cognitive skills could be the basis for a cognitive rehabilitation program after identifying which ones were relevant to specific behaviors.

Jaeger et al. (1992) have reviewed studies which indicate that neuropsychologic deficits correlate better with social and occupational functioning than diagnosis or symptomatology. They suggest that cognitive deficits may contribute to impaired social and occupational function and prevent acquisition of social skills. Previous studies have shown that capacity to work may be predicted by neuropsychologic tests (Heaton et al. 1978; Newnan et al. 1988; Weaver and Brooks 1963). This group also reported that "functionally disabled" affective disorder patients (unipolar or bipolar) who were unable to engage in work, education, or social activity had comparable neuropsychologic deficits in memory, attention, executive function, and motor performance to functionally disabled schizophrenics (Tigner et al. 1994). This suggests that cognitive deficits are not disease specific but do convey impaired social and work function. It is noteworthy that performance on the WCST was re- 
ported to be as abnormal in manic patients in a near recovered state as that of a group of stable chronic schizophrenic patients (Morice 1990).

Evidence supporting the greater importance of cognitive deficits than psychopathology to global and work function has emerged from studies of monozygotic twins discordant for schizophrenia. Goldberg et al. (1990) reported cognitive measures had low correlations with symptoms in the affected twins, whereas there were strong correlations between cognitive performance on tests such as IQ, continuous performance, WCST, and memory and general level of functioning on the GAS. They subsequently reported (Goldberg et al., 1993b) that intrapair differences in memory for stories, paired associates, verbal fluency, and Tower of Hanoi were related to GAS scores. Significant correlations of cognitive measures with positive and negative symptoms were fewer.

We have also examined the relationship between GAS scores and the four domains of cognitive function previously described (Kenny and Meltzer 1991): executive function, attention, recall memory, and verbal fluency in 174 schizophrenic patients, prior to treatment. The patients consisted of 76 treatment-resistant patients, and 98 nontreatment-resistant patients. Most were neuroleptic-free at the time of testing but were able to cooperate. The results will be presented in detail elsewhere. Briefly, the following tests were significantly correlated with GAS scores, listed in rank order of the strength of the relationship: the WCST-Category and Percent Perseveration, Digit Symbol Substitution Test, WISC-R Maze, VLL-Immediate Recall, Controlled Word Association, and Category Instance Generation. The VLL-Delayed Recall and Consonant Trigram test were not significantly correlated with the GAS scores. The Spearman $\rho$ ranged from 0.16 to 0.27 . Similarly, the Quality-of-Life Scale (QLS; Heinrichs et al. 1984) scores were correlated with most of the same tests (exceptions:
WISC-R Maze and VLL-Immediate Recall). However, the QLS score was correlated with the Consonant Trigram test. These correlations were more robust than those with the GAS ( $\rho=0.21$ to 0.36 ). The neuropsychology test scores correlated with negative symptoms rather than positive symptoms, in agreement with the results of Breier et al. (1991). Those correlations were stronger for the neuroleptic-resistant group than the neuroleptic-responsive group.

After 6 months of treatment of 48 neuroleptic-resistant patients with clozapine, the neuropsychologic battery, BPRS, GAS, and QLS were repeated. These data are given in Table 1.

The neuropsychologic test scores after 6 months on clozapine were correlated with GAS and QLS scores at 6 months (2), particularly WCST-Category and Percent Perseveration, VLL-Immediate Recall correlated with GAS regardless of severity symptoms; the Digit Symbol Substitution test and VLL-Delayed Recall correlated with QLS score, but much less so with psychopathology.

We also examined the relationship between work function and cognitive function at baseline in a group of 82 schizophrenic patients. Of this group, 15 were employed full-time or in school, 13 were employed parttime, and 54 were unemployed. The WCST-Category score was significantly higher in those employed fulltime (4.6 \pm SD 2.4) compared to the unemployed ( $2.8 \pm$ SD 2.3) and part-time employed (2.0 \pm SD 2.0). The following test scores were significantly better in those employed full-time at 12 months compared to the unemployed: WISC-R Maze, Controlled Word Association, Category Instance Generation, Digit Symbol Substitution Test, VLL-Immediate and Delayed Recall; however, the part-time employed did not differ from either of the other two groups. A similar pattern was obtained for 12 month neuropsychologic test scores that were available for 76 patients. Again, the WCST Category score best

Table 1. Correlations between Neuropsychologic Test Scores and Response Measures at 6 Months

\begin{tabular}{|c|c|c|c|c|c|}
\hline \multirow[b]{2}{*}{ Test } & \multicolumn{3}{|c|}{ BPRS } & \multirow[b]{2}{*}{ GAS } & \multirow[b]{2}{*}{ QLS } \\
\hline & Total & Positive & Negative & & \\
\hline WCST Category & - & - & - & $0.35^{d}$ & - \\
\hline WCST-Percent Perseveration & - & $-0.33^{b}$ & - & $-0.55^{d}$ & - \\
\hline WISC-R Maze & $-0.29^{b}$ & $-0.32^{a}$ & - & $0.49^{c}$ & $0.35^{b}$ \\
\hline Controlled Word Association & 一 & - & - & - & - \\
\hline Category Instance Generation & - & - & $-0.36^{b}$ & - & - \\
\hline Digit Symbol Substitution & 一 & - & - & 一 & $0.27^{a}$ \\
\hline VLL-Immediate Recall & - & - & - & $0.33^{b}$ & $0.33^{b}$ \\
\hline VLL-Delayed Recall & - & $-0.27^{a}$ & - & $0.25^{a}$ & $0.39^{b}$ \\
\hline
\end{tabular}

Abbreviations: WCST, Wisconsin Card Sorting Test; WISC-R, Wechsler Intelligent Scale for Children-Revised; VLL, Verbal List Learning.

${ }^{a} p<.10$.

${ }^{b} p<.05$.

${ }^{c} p<.001$.

$d_{p}<.0001$. 
discriminated the full-time employed from the other two groups.

In order to provide a global measure of impairment, the Mahalanobis D-Squared (MDS) (Mahalanobis and Seber, 1984) method was used. This procedure converts the individual test score into a single value that expresses the difference between the individual from the normal control, mean of the variances and covariances between the normal subjects, and determines the scale of the difference. It may also be regarded as a signed difference and is somewhat related to an average Z-score.

Using this measure, we found that the improvement in GAS score between baseline and 6 months, in 84 schizophrenic patients (including both neuroleptic-responsive and neuroleptic-resistant patients) after controlling for baseline BPRS Total score, was inversely related to impairment on the neuropsychologic test score as expressed by the MDS method $(p<.05)$. A similar finding was obtained for improvement in QLS at 6 months $(p=.02)$ in 63 patients. These data were obtained in patients treated either with clozapine or typical neuroleptic drugs. These results will be presented in detail elsewhere.

Thus, cognitive function appears to be an important predictor of work function, especially the WCST Category measure. Unlike Breier et al. (1991), the WCST-Percent Perseveration measure did not predict work function. It also did not correlate with GAS or QLS scores at 12 months in this group of patients or in nontreatmentresistant patients. The WCST has been suggested to provide a standardized measure of the ability to identify abstract categories and shift cognitive set (Berg 1948; Grant and Berg 1948). It was thought to provide a measure of frontal lobe damage (Grant and Berg 1948). On the basis of blood flow studies during the performance of this test, as well as attempts to teach correct performance to schizophrenic patients, Weinberger and colleagues (Weinberger et al. 1986; Berman et al. 1986; Goldberg et al. 1987) concluded that the impaired performance in schizophrenics was due to an abnormality in the dorsolateral prefrontal cortex. However, there is other evidence that deficits elsewhere than the frontal lobe are associated with poor performance on this test (Anderson et al. 1991). No specific region of the frontal lobe has been implicated, and some subjects with extensive frontal lobe damage perform well on the WCST.

We have found no effect of clozapine on performance on the WCST-Category or Percent Perseveration in treatment-resistant patients (Hagger et al. 1993; Lee et al. 1994). Similar results have been noted by Goldberg et al. (1992). However, the Percent WCST-Perseveration score improved with clozapine treatment in neuroleptic responders (Lee et al. 1994). We have found that clozapine improved performance on the WISC-R Maze, Controlled Word Association Tests, and so forth, tests that were significantly better in those patients with schizophrenia who were employed full-time compared to those not so employed. Because cognitive performance appears to be relevant to work performance, the ability of clozapine to bring about improvement in this domain may be of great value clinically. Goldberg et al. (1987) were unable to teach schizophrenic patients how to improve their performance on the WCST test, but three other studies have reported considerable improvement in performance (Goldman et al. 1992; Green et al. 1992; Stratta et al. 1994). It will be of interest to see if such learning can be facilitated by clozapine.

\section{CONCLUSIONS}

Cognitive deficits appear to be enduring characteristics of most schizophrenic patients. Although not specific for schizophrenia, they appear to develop early in the illness, perhaps even prior to the first psychotic manifestation. They persist during periods of remission. Social and work function and overall outcome may be better predicted by persistent cognitive deficits than by residual psychopathology. THE WCST test appears to be particularly useful as a predictor of capacity to work. Clozapine appears to be more effective than typical neuroleptics to improve some types of cognition, especially verbal fluency as measured by the Controlled Word Association test.

\section{ACKNOWLEDGMENT}

The research reported was supported in part by USPHS MH 41684, GCRC MO1RR00080, and the National Alliance for Research on Schizophrenia and Depression (NARSAD) as well as grants from the Elisabeth Severance Prentiss and John Pascal Sawyer Foundations and Stanley Foundation. H. Y. M. is the recipient of a USPHS Research Career Scientist Award MH 47808. The secretarial assistance of Ms. Lee Mason is greatly appreciated.

\section{REFERENCES}

Anderson SW, Damasio H, Jones RD, Tranel D (1991): Wisconsin Card Sorting Test Performance as a measure of frontal lobe damage. J Clin Exp Neuropsychol 13:909922

Bellack AS, Mueser KT, Morrison RL, Tierney A, Podell K (1990): Remediation of cognitive deficits in schizophrenia. Am J Psychiatry 147:1650-1655

Bellack AS (1992): Cognitive rehabilitation for schizophrenia: Is it possible? Is it necessary? Schizophr Bull 18:43-49

Berg EA (1948): A simple objective test for measuring flexibility in thinking. J Gen Psychol 39:15-22 
Berman KF, Zec RF, Weinberger DA (1986): Physiologic dysfunction of dorsolateral prefrontal cortex in schizophrenia, II: Role of neuroleptic treatment, attention, and mental effort. Arch Gen Psychiatry 43:126-135

Bilder RM, Lipschultz-Broch L, Reiter G, Geisler SH, Mayerhoff DI, Lieberman JA (1992): Intellectual deficits in first-episode schizophrenia: Evidence for progressive deterioration. Schizophr Bull 18:437-448

Bilder RM, Lipschultz-Broch L., Reiter G, Mayerhoff D, Loebel A, Degreef G, Ashtari M, Lieberman JA (1991): Neuropsychological studies of first-episode schizophrenia. Schizophr Res 4:381-382

Bilder RM, Turkel E. Lipschultz-Broch L, Lieberman JA (1992): Antipsychotic medication effects on neuropsychological function. Psychopharmacol Bull 28:353-366

Bilder RM, Mukherjee S, Rieder RO, Pandurangi AK (1985): Symptomatic and neuropsychological components of defect states. Schizophr Res 11:409-419

Braff DL, Heaton R, Kuck J, Cullum M, Moranville J, Grant I, Zisook S (1991): The generalized pattern of neuropsychological deficits in outpatients with chronic schizophrenia with hetergeneous Wisconsin Card Sorting Test Results. Arch Gen Psychiatry 48:891-898

Breier A, Schreiber JL, Dyer J, Pickar D (1991): National Institute of Mental Health longitudinal study of chronic schizophrenia. Arch Gen Psychiatry 48:239-246

Buchanan RW, Holstein C, Breier A (1994): The comparative efficacy and long-term effect of clozapine treatment of neuropsychological test performance. Biol Psychiatry 36:717-725

Cassens G, Inglis AK, Appelbaum PS, Gutheil TG (1990): Neuroleptics: Effects of neuropsychological function in chronic schizophrenic patients. Schizophr Bull 16:477499

Cleghorn JM, Kaplan RD, Szechtman B, Szechtman H, Brown GM (1990): Neuroleptic drug effects on cognitive function in schizophrenia. Schizophr Res 3:211-219

Erickson WD, Yellin AM. Hopwood JH, Realmuto GM, Greenberg LM (1984): The effects of neuroleptics on attention in adolescent schizophrenics. Biol Psychiatry 19:745-753

Goldberg TE, Greenberg RD, Griffin SJ, Gold JM, Kleinman JE, Pickar D, Schulz SC, Weinberger DR (1993a): The effect of clozapine on cognition and psychiatric symptoms in patients with schizophrenia. Br J Psychiatry 162: $43-48$

Goldberg TE, Ragland JD, Torrey EF, Gold JM, Bigelow LB, Weinberger DR (1990): Neuropsychological assessment of monozygotic twins discordant for schizophrenia. Arch Gen Psychiatry 47:1066-1072

Goldberg TE, Torrey EF, Gold JM, Ragland JD, Bigelow LNB, Weinberger DR (1993b): Learning and memory in monozygotic twins discordant for schizophrenia. Psychol Med 23:71-85

Goldberg TE, Weinberger DR (1988): Probing prefrontal function in schizophrenia with neuropsychological paradigms. Schizophr Bull 14:179-183

Goldberg TE, Weinberger DR, Berman KF, Pliskin NH, Podd MH (1987): Further evidence for dementia of the prefrontal type in schizophrenia? A controlled study of teaching the Wisconsin Card Sorting Test. Arch Gen Psychiatry 44:1008-1014

Goldman RS, Axelrod BN, Tompkins LM (1992): Effect of instructional cues on schizophrenic patients' performance on the Wisconsin Card Sorting Test. Am J Psychiatry 149:1718-1722

Grant DA, Berg EA (1948): A behavioral analysis of degree of reinforcement and ease of shifting to new responses in a Weigl type card sorting problem. J Exp Psychol 38:404411

Green MF, Satz P, Ganzell S, Vaclav JF (1992): Wisconsin Card Sorting Test performance in schizophrenia: Remediation of a stubborn deficit. Am J Psychiatry 149:62-67

Hagger C, Buckley P, Kenny JT, Friedman L, Ubogy D, Meltzer HY (1993): Improvement in cognitive functions and psychiatric symptoms in treatment-refractory schizophrenic patients receiving clozapine. Biol Psychiatry 34:702-712

Hawk AB, Carpenter WT Jr, Strauss JS (1975): Diagnostic criteria and 5 year outcome in schizophrenia. Arch Gen Psychiatry 32:343-347

Heaton RK, Cheline GJ, Lehman RAW (1978): Using neuropsychological and personality tests to assess the likelihood of patients' employment. J Nerv Ment Dis 166:408416

Heaton R, Paulsen JS, McAdams LA, Kuck J, Zisook S, Braff D, Harris MJ, Jeste DV (1994): Neuropsychological deficits in schizophrenics: Relationship to age, chronicity, and dementia. Arch Gen Psychiatry 51:469-476

Heinrichs DW, Hanlon TE, Carpenter WT Jr (1984): The Quality-of-Life Scale: An instrument for rating the schizophrenic deficit syndrome. Schizophr Bull 10:388398

Hoff AL, Riordan H, O’Donnell DW, DeLisi LE (1991): Crosssectional and longitudinal neuropsychological test results. Schizophr Res 5:183-210

Hoff AL, Riordan H, O'Donnell DW, Morris L, DeLisi LE (1992a): Neuropsychological functioning of first-episode schizophreniform patients. Am J Psychiatry 149:898-903

Hoff, AL, Riordan H, O'Donnell DW, Strizke P, Neal C, Boccio A, Anand A, DeLisi LE (1992b): Anomalous lateral sulcus asymmetry and cognitive function in first-episode schizophrenia. Schizophr Bull 18:257-272

Jaeger J, Berns S, Tigner A, Douglas E (1992): Remediation of neuropsychological deficits in psychiatric populations: Rationale and methodological considerations. Psychopharmacol Bull 28:367-390

Judson AJ, MacCasland BW (1960): The effects of chlorpromazine on psychological test scores. J Consulting Psychol 24:192

Kenny J, Meltzer HY (1991): Attention of higher cortical functions in schizophrenia. J Neuropsychiatr Clin Neurosci 3:269-275

King DJ (1990): The effect of neuroleptics on cognitive and psychomotor function. Br J Psychiatry 157:799-811

Lee MA, Thompson P, Meltzer HY (1994): Effects of clozapine on cognitive function in schizophrenia. J Clin Psychiatry 55(suppl B):82-87

Mahalanobis D, Seber GAF (1984): Multivariate Observations. New York, John Wiley and Sons, p 354 
Meltzer HY (1991): The mechanism of action of novel antipsychotic drugs. Schizophr Bull 17:263-287

Meltzer HY (1992): Dimensions of outcome with clozapine. Br J Psychiatry 160 (Suppl 17):46-53

Meltzer HY (1992b): Treatment of the neuroleptic nonresponsive schizophrenic patients. Schizophr Bull 18:515-542

Meltzer HY, Yamamoto BK, Lowy MT, Stockmeier CA (1995): The mechanism of action of atypical antipsychotic drugs: An update. In Watson SJ and Akil H (eds), Biology of Schizophrenia and Affective Disease ARNMD Series. New York, Raven Press, $p 73$ in press

Medalia A, Gold J, Merriam A (1988): The effects of neuroleptics on neuropsychological test results of schizophrenics. Arch Clin Neuropsychol 3:249-271

Morice R (1990): Cognitive inflexibility and prefrontal dysfunction in schizophrenia and mania. Br J Psychiatry 157:50-54

Mueser KL, Bellack AS, Douglas MS, Wade JH (1991): Prediction of social skill acquisition in schizophrenic and major affective disorder patients from memory and symptomatology. Psychiatr Res 37:281-296

Nestor PG, Faux SF, McCarley RW, Sands SF, Horvath TB, Peterson A (1991): Neuroleptics improve sustained attention in schizophrenia. A study using signal detection theory. Neuropsychopharmacology 4:145-149

Neuchterlein KH, Dawson ME (1984): Information processing and attentional functioning in the development course of schizophrenic disorders. Schizophr Bull 10:160203

Newnan OS, Heaton RK, Lehman RAW (1978): Neuropsychological and MMRI correlates of patient's future employment characteristics. Percept Motor Skills 46:635642

Oltmanns TF (1978): Selective attention in schizophrenia and manic psychoses: The effect of distraction on information processing. J Abnorm Psychol 87:212-225

Porteus SD (1957): Maze test reactions after chlorpromazine. J Consulting Psychol 21:15-20

Porteus SD, Barclay JE (1957): A further note on chlorpromazine: Maze Reactions. J Consulting Psychol 21:297299
Saykin AJ, Schtasel DL, Gur RE, Kester BD, Mozley LH, Stafiniak P, Gur RC (1994): Neuropsychological deficits in neuroleptic naive patients with first-episode schizophrenia. Arch Gen Psychiatry 51:124-131

Saykin AJ, Gur RC, Gur RE, Mozley D, Mozley LH, Resnick SM, Kester DB, Stafiniak P (1991): Neuropsychological function in schizophrenia. Selective impairment in memory and learning. Arch Gen Psychiatry 48:618-624

Seidman LH (1983): Schizophrenic and brain dysfunction: An integration of recent neurodiagnostic findings. Psychol Bull 94:195-238

Spitzer RL, Gibbon M, Endicott J (1979): Global Assessment Scale. New York, New York State Psychiatric Institute

Spohn HE, Strauss ME (1989): Relation of neuroleptic and anticholinergic medication to cognitive function in schizophrenia. J Abnorm Psychol 98:367-380

Stratta P, Mancini F, Mattei P, Casacchia M, Rossi A (1994): Information processing strategy to remediate Wisconsin Card Sorting Test performance in schizophrenia: A pilot study. Am J Psychiatry 151:915-918

Sweeney JA, Haas GL, Kelip JG, Long M (1991): Evaluation of the stability of neuropsychological functioning after acute episodes of schizophrenia: One-year follow-up study. Psychiatry Res 38:63-76

Sweeney JA, Haas GL, Li S (1992): Neuropsychological and eye movement abnormalities in first-episode and chronic schizophrenia. Schizophr Bull 18:283-293

Tigner A, Jaeger J, Berns S, Rastogi R (1994): Neuropsychological tests fail to distinguish between schizophrenia and functionally disabled affective disorder patients seeking rehabilitation. Presented at International Neuropsychological Society, Cincinnati, Ohio, Abstract, p 140, February

Weaver LA, Brooks GW (1963): The use of psychomotor tests in predicting the potential of chronic schizophrenics. J Neuropsychiatry 5:170-180

Weinberger DR, Berman KS, Zec RF (1986): Physiological dysfunction of dorsolateral prefrontal cortex in schizophrenia, I: Regional cerebral blood flow evidence. Arch Gen Psychiatry 43:114-124 